\title{
Protein Kinase A Activity May Kinetically Upregulate the Striatal Transporter for Dopamine
}

\author{
Melissa Batchelor ${ }^{1}$ and James O. Schenk ${ }^{1,2,3}$ \\ Departments of ${ }^{1}$ Chemistry and ${ }^{2}$ Biochemistry and Biophysics, and ${ }^{3}$ Programs in Pharmacology/Toxicology and \\ Neuroscience, Washington State University, Pullman, Washington 99164
}

\begin{abstract}
The neuronal dopamine transporter (DAT) plays a key role in terminating dopaminergic chemical neurotransmission; thus, the study of the regulation of DAT activity is important in defining parameters relevant to the control of dopaminergic neurotransmission. Interpretation of the results from previous work of this laboratory suggests that occupation of presynaptic autoreceptors increases DAT activity. Second messenger signaling related to kinetic upregulation of DAT has not been examined previously. However, others have shown that protein kinase $\mathrm{C}$ activity may downregulate DAT activity, whereas protein kinase $A$ has shown variable results. Herein it is shown that protein kinase A activity mediates the kinetic upregulation of DAT. Quinpirole increased DAT activity that was blocked by sulpiride and the protein kinase A selective inhibitor $\mathrm{H}-89$. Brief
\end{abstract}

incubations with forskolin and 8-bromo-cAMP (8-Br-cAMP) were found to stimulate striatal DAT activity by increasing the $V_{\max }$ of transport without affecting the $K_{\mathrm{m}}$. Exposures $>15 \mathrm{~min}$ had no effect. The 8-Br-cAMP-stimulated increases in DAT activity were blocked by pre-exposure to $\mathrm{H}-89$. Thus, second messenger signaling via the CAMP cascade may mediate kinetic upregulation of DAT. Kinetic analyses of the results suggest that either insertion of DAT into the membrane or activation of pre-existing DAT within the membrane mediates the regulation.

Key words: dopamine transporter; protein kinase A; rotating disk electrode voltammetry; striatum; 8-Br-cAMP; forskolin; quinpirole; sulpiride; $\mathrm{H}-89 ; \mathrm{H}-7 ; \mathrm{H}-9$
It has been suggested in recent reports that the activity of the transporter for dopamine (DAT) may be regulated (for review, see Reith et al., 1997). Various stimuli have been shown to produce changes in the kinetic activity of DAT including: increases in DAT activity after receptor occupation of the presynaptic receptors of the $\mathrm{D}_{2}$ type (Meiergerd et al., 1993; Cass and Gerhardt, 1994); persistent kinetic changes after withdrawal from treatments with cocaine (Yi and Johnson, 1990; Meiergerd et al., 1994a,b; Meiergerd et al., 1997); and decreases and increases in DAT activity by a variety of compounds involved in second messenger signaling (Pierce and Kalivas, 1997; Reith et al., 1997; Z hu et al., 1997). In addition, high and low responding animals in a behavioral model exhibit differences in DAT activity (Hooks et al., 1994). The cloned rat and human DATs possess consensus sites for phosphorylation by cAMP-dependent protein kinases and by protein kinase $\mathrm{C}$ in the $\mathrm{N}$ - and $\mathrm{C}$-terminal domains and third extracellular loop (Giros and Caron, 1993). Most studies of the effects of second messenger systems on DAT kinetic activity have focused on the effects of protein kinase $\mathrm{C}$ activity on DAT activity by studying the intracellular accumulation of $\left[{ }^{3} \mathrm{H}\right]$ dopamine in cell culture systems expressing DAT and in synaptosomes (Huff et al., 1997; Vaughn et al., 1997; Zhang et al., 1997; Zhu et al., 1997). The results suggest that stimulation of protein kinase $C$

\footnotetext{
Received June 25, 1998; revised Sept. 29, 1998; accepted Sept. 30, 1998.

This work was supported by the State of Washington and grants from the National Institute on Drug Abuse (NIDA) to J.O.S. (RO1 DA07384). J.O.S. is a recipient of an NIDA Research Scientist Development Award (KO2 DA00184) and M.B. was supported by a fellowship from the Howard Hughes Medical Institute.

Correspondence should be addressed to Dr. James O. Schenk, Department of Chemistry, Washington State University, Pullman, WA 99164-4630.

Ms. Batchelor's present address: Department of Chemistry, University of Michigan, Ann Arbor, MI.

Copyright (C) 1998 Society for Neuroscience $\quad 0270-6474 / 98 / 1810304-06 \$ 05.00 / 0$
}

downregulates the kinetic activity of DAT by decreasing the $V_{\max }$ of accumulation. Others have reported that stimulation of protein kinase $\mathrm{C}$ activity increases DAT-mediated release of dopamine (see Giambalvo, 1992; Kantor and Gnegy, 1998 and references therein). A couple of reports suggesting that calciumcalmodulin-dependent protein kinases may upregulate DAT have appeared recently (Uchikawa et al., 1995; Pierce and Kalivas, 1997), and an earlier report has shown that the cAMP-dependent protein kinase, protein kinase $\mathrm{A}$, upregulates $\left[{ }^{3} \mathrm{H}\right]$ dopamine accumulation by DAT (Kadawaki et al., 1990). Other investigations report that this protein kinase failed to affect DAT activity (Tian et al., 1994; Copeland et al., 1996; Zhu et al., 1997). Because DAT can be upregulated by a variety of stimuli, and others have shown kinetic upregulation of DAT by protein kinase A, we examine this issue further. Herein we describe results of studies of the effects of protein kinase A on the kinetically resolved inwardly directed activity of striatal DAT as measured by rotating disk electrode voltammetry. Because this approach monitors the clearance of extracellular concentrations of dopamine $\left([\mathrm{DA}]_{\mathrm{o}}\right)$, it provides a window for observing what presynaptic and postsynaptic receptors may "see" after alterations in DAT kinetic activity and a much shorter window of observation of the kinetic activity of DAT than traditional assays with $\left[{ }^{3} \mathrm{H}\right]$ dopamine. As will be shown, it was found that protein kinase A activity transiently upregulates DAT activity. Kinetic analyses suggest that insertion of DAT into the neuronal membrane or activation of previously inactive DAT within the membrane likely mediates the kinetic upregulation.

\section{MATERIALS AND METHODS}

Rotating disk electrode (RDE) voltammetric monitoring of the velocity of the transporter for dopamine into striatal suspensions in $500 \mu \mathrm{l}$ of physiological buffer were conducted as previously described (Meiergerd 
and Schenk, 1995; Earles et al., 1998). Tissue suspensions were prepared from striata obtained from rapid decapitation of male, 275-325 gm, Sprague Dawley rats. Rats were not pretreated with any drug before experimentation, and the animal protocols used were reviewed and approved by the University Animal Care and Use Committee. The potentiostat was a Bioanalytical Systems Inc. (West Lafayette, IN) model LC3D (Petite Ampére) with a time constant (5RC) changed (details available on request) to $200 \mathrm{msec}$. The RDE controller and glassy carbon electrode were purchased from Pine Instruments Inc. (Grove City, PA), and the electroanalytical parameters used were: $\mathrm{E}_{\text {app }}=+450 \mathrm{mV}$ versus $\mathrm{Ag}-\mathrm{AgCl}$ and a rotation rate of $2000 \mathrm{rpm}$ with current outputs fed to a Nicolet (Madison, WI) model 2090 digital oscilloscope.

The initial velocities of transport $(\nu)$ were defined and measured as previously described (Meiergerd and Schenk, 1995), and values of $K_{\mathrm{m}}$ and $V_{\max }$ were estimated by fitting experimentally observed values of $\nu$ versus $[\mathrm{DA}]_{\mathrm{o}}$ to the Michaelis-Menten expression using commercially available nonlinear curve-fitting software (GraphPad Prism, San Diego, CA). Indicators of the precision of the resulting kinetic parameters are standard errors of regression (SER), and statistical comparisons of the results were made using a $z$ test (Havlicek and Crain, 1988). More detailed analyses of changes observed in the kinetic parameters were based on treatments by Fersht (1985) and Segel (1993).

All concentrations reported are final molarities in the incubation chamber. Inhibition studies were conducted by pre-exposing the tissue to an inhibitor dissolved in physiological buffer at a concentration 10-fold higher than its $\mathrm{IC}_{50}$. Exposure times were between 12 and $15 \mathrm{~min}$. In experiments with 8-bromo-cAMP (8-Br-cAMP), 8-Br-cAMP $(50 \mu \mathrm{M})$ was added $1 \mathrm{~min}$ before dopamine. Forskolin and 1,9-dideoxyforskolin experiments were performed at $50 \mu \mathrm{M}$. Stock concentrations of these agents were made in dimethylsulfoxide. The quinpirole experiments were conducted at $0.1 \mu \mathrm{M}$ quinpirole by adding it $30 \mathrm{sec}$ before dopamine, as described previously (Meiergerd et al., 1993). Sulpiride was added 5 min before dopamine.

Chemicals, solutions, and drugs. All solutions used in these studies were made in university-supplied deionized water that was purified further with a Nanopure (Barnstead, Dubuque, IA) water purification system. The common buffer salts were purchased from Baker Chemical Co. (Philipsburg, NJ). Forskolin, 1,9-dideoxyforskolin, dopamine (DA), 8-Br-cAMP, quinpirole (QUIN), sulpiride (SULP), 1-(5-isoquinolinesulfonyl)-2-methylpiperazine $\mathrm{HCl}$ (H-7), and $N$-[2-(methylamino) ethyl]-5-isoquinolinesulfonamide $\mathrm{HCl}(\mathrm{H}-9)$ were purchased from Research Biochemicals (Natick, MA). Bisindolylmaleimides and $N$-[2(( $p$-bromocinnamyl)amino)ethyl]-5-isoquinolinesulfonamide $\mathrm{HCl}(\mathrm{H}$ 89) were purchased from Calbiochem-Novabiochem (La Jolla, CA). A bicarbonate-based physiological buffer at $37^{\circ} \mathrm{C}$ and $\mathrm{pH} 7.4$ was used in these experiments (composition in mM: $124 \mathrm{NaCl}, 1.80 \mathrm{KCl}, 1.24$ $\mathrm{KH}_{2} \mathrm{PO}_{4}, 1.30 \mathrm{MgSO}_{4}, 2.50 \mathrm{CaCl}_{2} \cdot 2 \mathrm{H}_{2} \mathrm{O}, 26.0 \mathrm{NaHCO}_{3}$, and 10.0 glucose).

\section{RESULTS}

Figure 1 shows that $100 \mathrm{~nm}$ quinpirole increases the inwardly directed transport of dopamine in striatal suspensions and that the increased velocity of transport is blocked by $5 \mu \mathrm{M}$ sulpiride and pre-exposure to the nonselective protein kinase inhibitor H-9. H-89, a selective inhibitor of protein kinase A, at $500 \mathrm{~nm}$, also blocked the effect of quinpirole. Thus, the effect of the cAMP pathway on DAT activity was examined in more detail by measuring the kinetic parameters of dopamine transport under different treatment conditions. The control values of $K_{\mathrm{m}}$ and $V_{\max }$ were found to be close to those reported previously for this type of transport experiment (Meiergerd and Schenk, 1994; Wayment et al., 1998). The numerical results for the control studies and other analyses estimated from data obtained under the other treatment conditions along with the values of SER are listed in Table 1 . In preliminary studies $(n \geq 5)$ to set conditions for these experiments it was found that forskolin (at $50 \mu \mathrm{M}$ ) increased DAT activity at $4 \mu \mathrm{M}$ dopamine from $793 \pm 25 \mathrm{pmol} \cdot \mathrm{sec}^{-1} \cdot \mathrm{gm}^{-1}$ in controls to $903 \pm 72 \mathrm{pmol} \cdot \mathrm{sec}^{-1} \cdot \mathrm{gm}^{-1}$ after a 1 min incubation, whereas at a longer incubation time (15 min as used by others in the study of protein kinase $\mathrm{C}$ effects, vide ante) the transport value was lower at $786 \pm 110 \mathrm{pmol} \cdot \mathrm{sec}^{-1} \cdot \mathrm{gm}^{-1}$. Values ob-

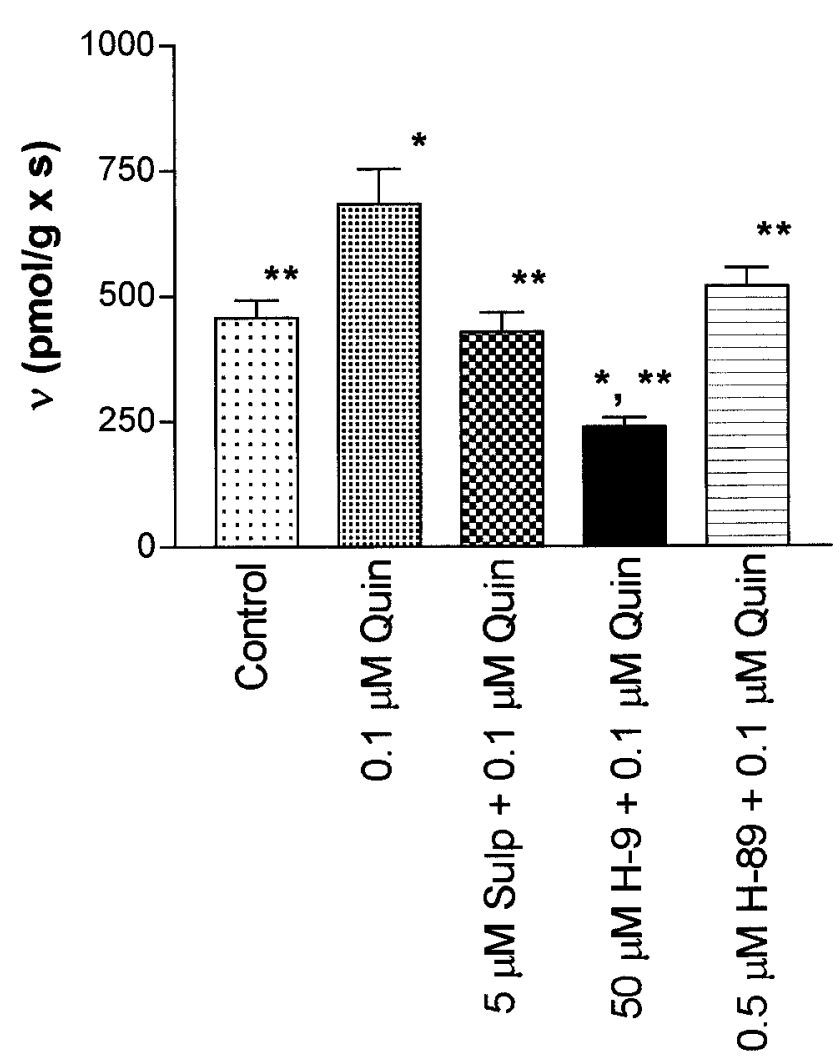

Figure 1. Upregulation of DAT activity by QUIN is blocked by SULP and protein kinase inhibitors. The transport velocity of an instantaneous pulse of $1.0 \mu \mathrm{M}$ dopamine was measured. The kinetic upregulation of striatal DAT activity by the dopamine agonist QUIN $(684 \pm 70 ; n=5)$ is reversed by the dopamine antagonist SULP ( $428 \pm 38 ; n=6)$, the nonselective protein kinase inhibitor H-9 $(238 \pm 18)$, and the selective protein kinase A inhibitor H-89 (519 $\pm 36 ; n=15)$. The bars represent values of SEM. The single asterisks indicate a difference from the control at $p \leq 0.01$, and the double asterisks indicate a difference from QUIN at $p \leq 0.01$ via a $z$ test. Each $n$ value represents a single experiment conducted with a single striatum.

served at 12 min of incubation were intermediate in value at $714 \pm 99 \mathrm{pmol} \cdot \mathrm{sec}^{-1} \cdot \mathrm{gm}^{-1}$. Thus, the greatest numerical difference (the largest increased observed velocity) with the best precision was observed at the 1 min incubation time, and this condition was used throughout the remainder of the study. Figure 2 shows that forskolin, when compared with results obtained with the inactive forskolin derivative 1,9-dideoxyforskolin increases the inwardly directed transport of dopamine by increasing the $V_{\text {max }}$ of transport. No statistically significant change in the $K_{\mathrm{m}}$ of the transport of dopamine was observed, and the $V_{\max } / K_{\mathrm{m}}$ quotient was not different from controls (Table 1).

In preliminary experiments $(n \geq 3)$ to set conditions for studies with $50 \mu \mathrm{M} 8$-Br-cAMP, it was found that DAT activity at $1.0 \mu \mathrm{M}$ dopamine was increased to $579 \pm 41 \mathrm{pmol} \cdot \mathrm{sec}^{-1} \cdot \mathrm{gm}^{-1}$ from the control value of $457 \pm 35 \mathrm{pmol} \cdot \mathrm{sec}^{-1} \cdot \mathrm{gm}^{-1}$. However, when incubations with 8-Br-cAMP were conducted for $12 \mathrm{~min}$ before adding dopamine, the observed velocity, $469 \pm 27$ $\mathrm{pmol} \cdot \mathrm{sec}^{-1} \cdot \mathrm{gm}^{-1}$, was found to be statistically indistinguishable from the control value. Thus, in subsequent experimentation 8-Br-cAMP was added $1 \mathrm{~min}$ before dopamine. Figure 3 illustrates that 8-Br-cAMP kinetically upregulates the striatal transport of dopamine by increasing the value of $V_{\max }$. No change in the value of $K_{\mathrm{m}}$ or the $V_{\max } / K_{\mathrm{m}}$ quotient was observed (Table 1 ). 
Table 1. Effects of agents modifying the activity of protein kinases on kinetic parameters of the inwardly directed transport of dopamine into striatal suspensions

\begin{tabular}{lccc} 
Treatment $^{a}$ & $\begin{array}{l}V_{\max } \\
\left(\mathrm{pmol} \cdot \mathrm{gm}^{-1} \cdot \mathrm{sec}^{-1}\right)\end{array}$ & $K_{\mathrm{m}}(\mu \mathrm{M})$ & $V_{\max } / K_{\mathrm{m}}$ \\
\hline Control & $976 \pm 67$ & $0.98 \pm 0.18$ & $996 \pm 195$ \\
Forskolin & $1152 \pm 92^{*}$ & $1.10 \pm 0.23$ & $1047 \pm 234$ \\
1,9-Dideoxyforskolin & $927 \pm 54$ & $0.82 \pm 0.13$ & $1130 \pm 190$ \\
8-Br-cAMP & $1294 \pm 83^{* *}$ & $1.30 \pm 0.20$ & $995 \pm 165$ \\
8-Br-cAMP + H-7 & $672 \pm 60^{* *}$ & $2.04 \pm 0.38^{* *}$ & $329 \pm 68^{* *}$ \\
8-Br-cAMP + H-9 & $742 \pm 91^{* *}$ & $2.20 \pm 0.55^{* *}$ & $337 \pm 93^{* *}$ \\
8-Br cAMP + H-89 & $1072 \pm 53$ & $1.31 \pm 0.16$ & $818 \pm 108$ \\
H-7 & $662 \pm 82^{* *}$ & $1.58 \pm 0.47$ & $419 \pm 135^{* *}$ \\
H-9 & $703 \pm 46^{* *}$ & $1.56 \pm 0.23$ & $450 \pm 72^{* *}$ \\
H-89 & $777 \pm 57^{* *}$ & $0.89 \pm 0.18$ & $873 \pm 188$ \\
\hline
\end{tabular}

*Different from its control, 1,9 dideoxyforskolin, at the $99 \%$ confidence level via a $z$ test.

**Difference from control at the $\geq 97 \%$ confidence level via a $z$ test.

${ }^{a}$ All agents were used at $50 \mu \mathrm{M}$ except $\mathrm{H}-89$, which was used at a protein kinase A-selective concentration of $500 \mathrm{~nm}$.
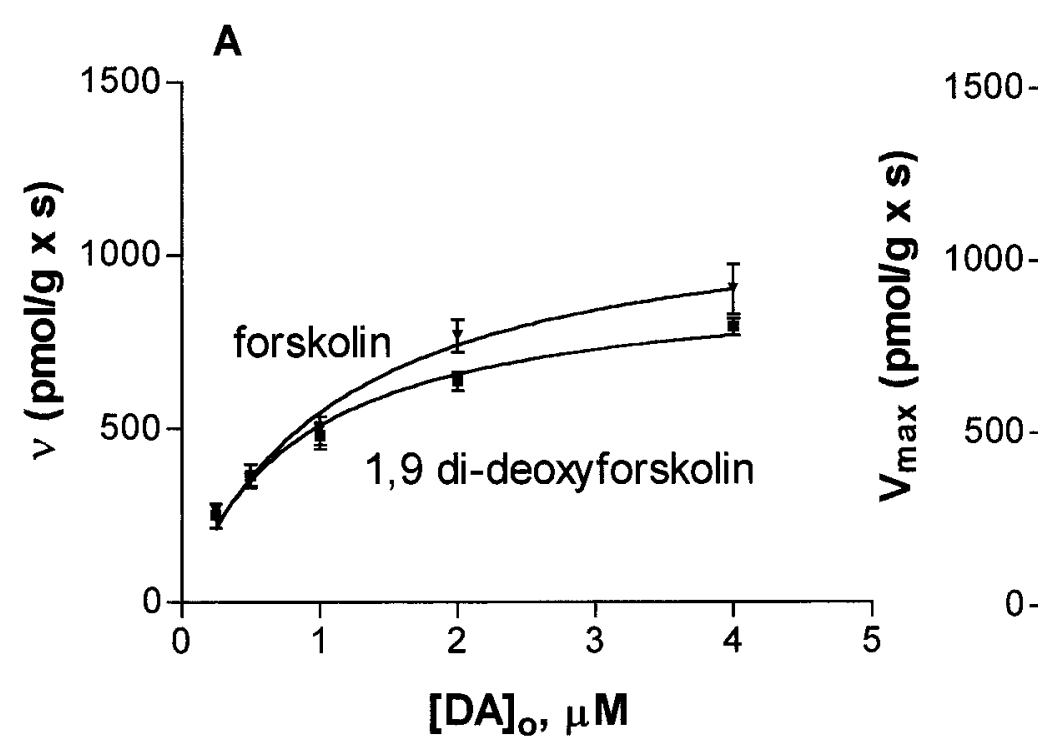

B 


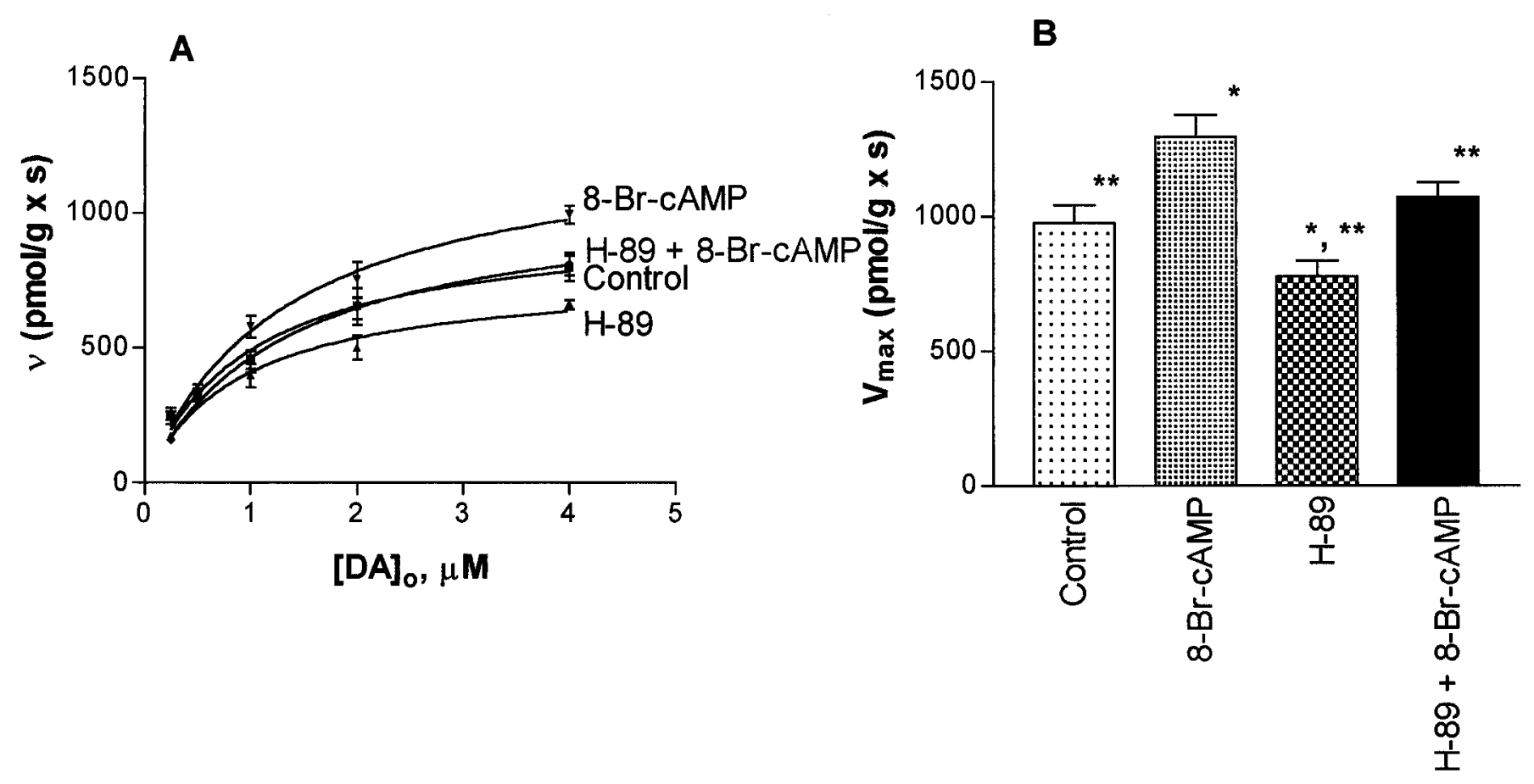

Figure 3. Protein kinase A mediates a kinetic upregulation of DAT. $A$ shows Michaelis-Menten curves obtained in the presence of 8-Br-cAMP alone and in the presence of 8-Br-cAMP and H-89. Each point represents $n$ values of $10-20$. Each $n$ value represents a single experiment conducted with a single striatum. $B$ shows the effects of protein kinase A on the $V_{\max }$ of transport. The experimental conditions and numerical results for the estimated $V_{\max } \pm \mathrm{SER}$ are (in pmol $\cdot \mathrm{sec}^{-1} \cdot \mathrm{gm}^{-1}$ wet weight): control, $976 \pm 67$; 8-Br-cAMP, $(50 \mu \mathrm{M}, 1$ min before DA) $1294 \pm 83$; H- 89 (0.5 $\mu \mathrm{M}$, exposure $\sim 15$ min before DA) plus 8-Br-cAMP (50 $\mu \mathrm{M}, 1$ min before DA), $1072 \pm 53$; and H-89, $(0.5 \mu \mathrm{M}$, exposure $\sim 15$ min before DA) $777 \pm 57$. The error bars represent the SER, and the single asterisks indicate differences from controls at $p \leq 0.02$ via a $z$ test. The double asterisks represent differences from 8 -Br-cAMP at $p \leq 0.02$ also via a $z$ test.

nonselective protein kinase inhibitor $\mathrm{H}-9$, as well as by the protein kinase A inhibitor H-89. Further work showed that activation of adenylate cyclase with forskolin or the addition of the membranesoluble cAMP analog 8-Br-cAMP also produced an $\mathrm{H}-89$ sensitive kinetic upregulation of the striatal transport of dopamine. H-89 alone was found to kinetically downregulate the transport of dopamine, however, this effect could be modulated by addition of 8 -Br-cAMP. Taken together, these results suggest that a cAMP-dependent protein kinase, protein kinase A, functions to upregulate the striatal transporter for dopamine. The lack of effect on the ratio, $V_{\text {max }} / K_{\mathrm{m}}$, is taken as evidence that the kinetic upregulation is not the result of a change in the kinetic state of DAT. However, this conclusion may be a result of propagation of error in the analyses. The nonselective inhibitors of protein kinases $\mathrm{H}-7$ and H-9 reduced $V_{\max }$ and the $V_{\max } / K_{\mathrm{m}}$ ratio, suggesting that the downregulation observed was accompanied by a change in the state DAT. When protein kinase $\mathrm{C}$ activity was inhibited selectively the transport activity of DAT was found to increase, a finding consistent with those previously reported for the effects of altering protein kinase $\mathrm{C}$ activity on DAT activity (vide ante) in which activation of protein kinase $\mathrm{C}$ resulted in a reduction of $V_{\text {max }}$.

\section{Comments on the changes in DAT mediated by protein kinase activity}

An analysis of the observed kinetic results can suggest what changes in interactions between dopamine and DAT occur as result of the activity of protein kinases. The possibilities for a change in kinetic activity include changes in $K_{\mathrm{m}}, V_{\max }$, or both. The results obtained here with protein kinase A indicate that only
$V_{\max }$ is changed by the activity of the kinase. The significance of this change can be examined in more detail. In treatments of Michaelis-Menten kinetics the catalytic activity is depicted by the reaction sequence:

$$
\mathrm{DA}+\mathrm{T} \underset{k_{1}}{\stackrel{k_{-1}}{\rightleftarrows}} \mathrm{DAT} \stackrel{k_{2}}{\longrightarrow} \mathrm{DA}+\mathrm{T}
$$

where $\mathrm{T}$ signifies the transporter, DA signifies dopamine, DAT signifies the dopamine-occupied transporter, $k_{1}$ is the second order rate constant of association of DA with $\mathrm{T}, k_{-1}$ is the first order dissociation rate constant of DA from DAT, and $k_{2}$ is the first order rate constant of the catalytic cycle of the transport of dopamine across the membrane. In the classical kinetic treatment of this model the interaction of DA with $\mathrm{T}$ is considered to be rapid and reversible, and the transport event occurs as a second step signified by $k_{2}$ (Fersht, 1985). The well known steady state analysis yields the Michaelis-Menten expression where $K_{\mathrm{m}}=$ $[\mathrm{DA}][\mathrm{T}] /[\mathrm{DAT}]=k_{-1} / k_{1}$, the dissociation constant of DA from DAT $\left(K_{\mathrm{DA}}\right)$ and $V_{\max }=k_{2} \times$ the concentration (or density) of the transporter. In the case in which $k_{2} \gg k_{-1}$ (the BriggsHaldane kinetic condition) the $K_{\mathrm{m}}=K_{\mathrm{DA}}+k_{2} / k_{1}$, the $V_{\max }$ has the same significance as before, and the rate constants of association of DA with $\mathrm{T}$ should be in the $10^{7}-10^{8} \mathrm{sec}^{-1} \mathrm{M}^{-1}$ range (Fersht, 1985). Results of previous work by this laboratory (Meiergerd and Schenk, 1994; Meiergerd et al., 1994b) suggest that the kinetics of striatal DAT follows the Briggs-Haldane model (Fersht, 1985; Segel, 1993) because the second order rate constant of association of dopamine with DAT was in the range 


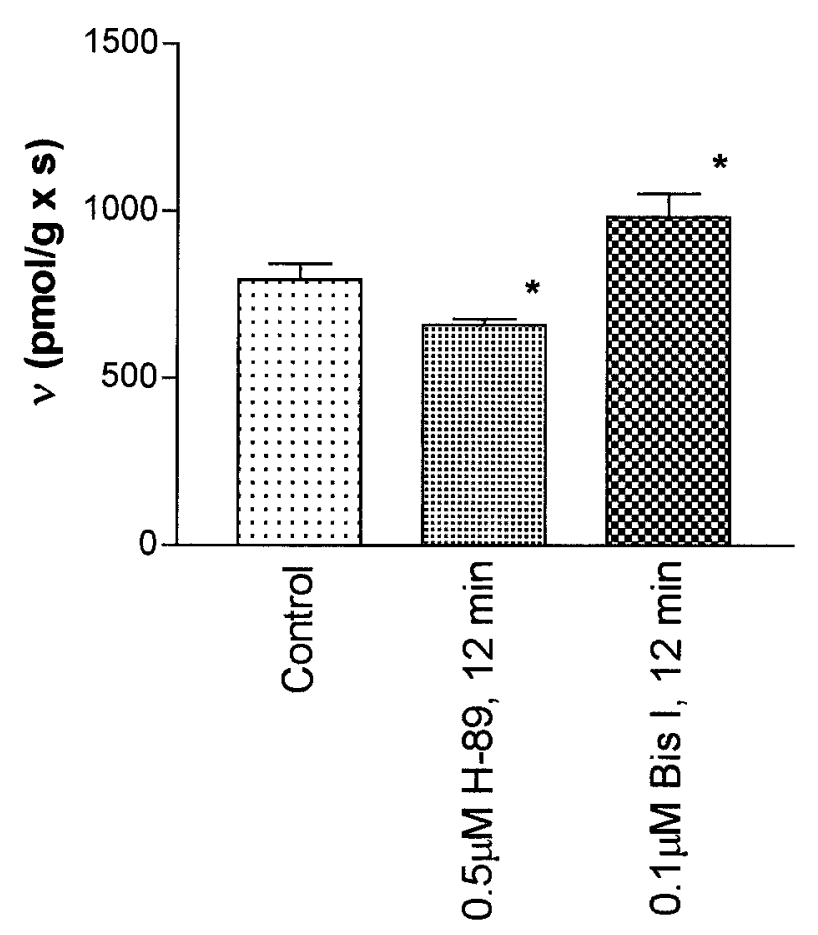

Figure 4. Protein kinase $\mathrm{C}$ and protein kinase A exhibit opposing effects on the velocity of DAT. Bisindolylmaleimide I (exposure $\geq 15 \mathrm{~min}$ ), a protein kinase $\mathrm{C}$ inhibitor, produced an increase in DAT activity. The results with $\mathrm{H}-89$, a selective protein kinase A inhibitor, were statistically lower than the controls under similar experimental conditions. Each experiment was conducted by measuring the transport velocity of an instantaneous pulse of $4.0 \mu \mathrm{M}$ dopamine, to estimate an effect on the value of $V_{\text {max }}$. The numerical values (in $\mathrm{pmol} \cdot \mathrm{sec}^{-1} \cdot \mathrm{gm}^{-1}$ wet weight) were: control, $796 \pm 47, n=23$; bisindolylmaleimide I, $983 \pm 70, n=7$; and H-89, $661 \pm 17, n=5$. The bars represent values of SER. The single asterisks indicate a difference from the controls at $p \leq 0.03$ via a $z$ test. The $n$ values represent a single experiment conducted with a single striatum.

indicated above for the Briggs-Haldane condition. Indeed, similar conclusions from a different line of argument have been made by Prof. Reith's laboratory (Zimanyi et al., 1989). Thus, if the kinetics of transport are changed, but no change in the dissociation constant occurs, then $k_{2}$ should be the only parameter changed, and both the values of $K_{\mathrm{m}}$ and $V_{\text {max }}$ should be altered by the change in kinetic state. Alternatively, if the density of DAT is altered by a regulatory event but not the dissociation constant for dopamine, then a change in $V_{\max }$ would be the result with no change in the $K_{\mathrm{m}}$. Finally, a change in $K_{\mathrm{DA}}$ as an effect would be reflected by a change in $K_{\mathrm{m}}$ only. Thus, in examining the values of the kinetic parameters in Table 1 , it can be hypothesized with reasonable kinetic support that upregulation of DAT activity by forskolin and 8-Br-cAMP may be mediated by a change in the density of active DAT because no change in $K_{\mathrm{m}}$ was observed. In one model in an expression system it has been shown that changes in $V_{\max }$ of human DAT result from activation of previously inactive DAT within the membrane (Pristupa et al., 1998). In the apparent downregulation of DAT activity by H-89, it may be concluded that the density of active DAT within the membrane was altered as well because there was a change (in the opposite direction) involving $V_{\max }$ only. These results suggest that protein kinase A may mediate control of membrane trafficking of DAT or activate otherwise inactive DAT within the membrane. In contrast to the findings with inhibition of protein kinase A, it was observed that the use of nonselective protein kinase inhibitors
H-7 and H-9, presumably inhibiting both protein kinase $\mathrm{A}$ and protein kinase $\mathrm{C}$, results in a diminution of $V_{\max }$ as well as an increase in $K_{\mathrm{m}}$, suggesting that binding of dopamine to the transporter as well as a reduction in the density and/or the value of $k_{2}$ occurred.

\section{Comparison to the findings of other investigators}

These findings agree with those of Kadawaki et al. (1990), Uchikawa et al. (1995), and Pierce and Kalivas (1997) in that protein kinase activity can kinetically upregulate DAT activity and appear to contrast with those of some others investigating the effects protein phosphorylation on the activity DAT (Tian et al., 1994; Copeland et al., 1996; Zhu et al., 1997). These later investigators have focused on the effects of protein kinase $\mathrm{C}$ activity on DAT activity. However, those investigating the effects of protein kinase A within their paradigms (i.e., incubation times, periods of monitoring effects, the study of accumulation, etc.) used in the study of protein kinase $\mathrm{C}$ have found no effects of forskolin and/or $8-\mathrm{Br}$ cAMP on DAT activity. We observe here that the effects of these agents occur rapidly (within a minute or so), and appear to be transient because the effect of DAT activity is diminished or unobservable after $\sim 12-15 \mathrm{~min}$. Furthermore, data consistent with others on effects of protein kinase $\mathrm{C}$ activity were observed in the present study. The cited investigators used paradigms outside the time window of $1 \mathrm{~min}$ used here for exposure times to protein kinase A activators, and it may be assumed that the results here are not in direct contrast with those of others; the differences observed may simply be a consequence of the different time windows of observation.

In conclusion, it is hypothesized that protein kinase A upregulates DAT by increasing the density of active DAT within the membrane. These results could be confirmed with binding experiments. However, binding experiments are difficult to perform on very short time scales at the present time. As studied by others and consistent with the data presented here, protein kinase $\mathrm{C}$ has the opposite effect on DAT. Combined, DAT may be regulated by protein kinase $\mathrm{A}$ in addition to protein kinase $\mathrm{C}$, but in apparent opposite directions. These two phosphorylating systems are thought to act independently and, when present simultaneously, not on the same substrate. Indeed, Vaughn et al. (1997) have shown that 8-Br-cAMP and forskolin-stimulated protein kinase A activity did not result in observable phosphorylation of DAT. Taken together it may be assumed, as has been suggested by Reith et al. (1997), that the substrates acted on by these two systems are different and that one, the protein kinase $\mathrm{C}$ system, may be involved in downregulating the activity of DAT via direct phosphorylation of DAT protein. In contrast, the protein kinase A system may upregulate DAT activity by phosphorylation of members of another biochemical control pathway.

\section{REFERENCES}

Cass WA, Gerhardt GA (1994) Direct evidence that D2 dopamine receptors can modulate dopamine uptake. Neurosci Lett 176:259-263.

Copeland BJ, Vogelsberg V, Neff NH, Hadjiconstantinou M (1996) Protein kinase $\mathrm{C}$ decreases uptake into striatal synaptosomes. J Pharmacol Exp Ther 277:1527-1532.

Earles C, Wayment H, Green M, Schenk JO (1998) Resolution of biogenic amine transporter kinetics by rotating disk electrode voltammetry: methodology and mechanistic interpretations. Methods Enzymol 296:660-675.

Fersht A (1985) Enzyme structure and mechanism, Ed 2. New York: W. H. Freeman.

Giambalvo CT (1992) Protein kinase C and dopamine transport-1. Effects of amphetamine in vivo. Neuropharmacology 31:1201-1210. 
Giros B, Caron MG (1993) Molecular characterization of the dopamine transporter. Trends Pharmacol Sci 14:43-49.

Havlicek LL, Crain RD (1988) Practical statistics for the physical sciences. Washington DC: American Chemical Society.

Hooks MS, Juncos JL, Justice JB, Meiergerd SM, Povlock SL, Schenk JO, Kalivas PW (1994) Individual and locomotor response to novelty predicts selective alterations in $\mathrm{D}_{1}$ and $\mathrm{D}_{2}$ receptors and mRNA's differences. J Neurosci 14:6144-6152.

Huff RA, Vaughn RA, Kuhar MJ, Uhl GR (1997) Phorbol esters increase dopamine transporter phosphorylation and decrease transport $V_{\max }$. J Neurochem 68:225-232.

Kadawaki K, Hirota K, Kioke K, Kiyama A, Tanizawa O (1990) Adenosine $3^{\prime}, 5^{\prime}$-cyclic monophosphate enhances dopamine accumulation in rat hypothalamic cell culture containing dopaminergic neurons. Neuroendocrinology 52:256-261.

Kantor L, Gnegy ME (1998) Protein kinase C inhibitors block amphetamine-mediated dopamine release in rat striatal slices. J Pharmacol Exp Ther 284:592-598.

Meiergerd SM, Schenk JO (1994) Striatal transporter for dopamine: catechol structure-activity studies and susceptibility of chemical modification. J Neurochem 62:998-1008.

Meiergerd SM, Schenk JO (1995) Measurement of the time-resolved kinetics of biogenic amine release and transporter activity by rotating disk voltammetry in vitro. Neuromethod 27. In: Voltammetric methods in brain systems (Boulton AA, Baker G, Adams RN, eds), pp 305-337. Totowa, NJ: Humana.

Meiergerd SM, Patterson TA, Schenk JO (1993) $\mathrm{D}_{2}$ receptors may modulate the function of the striatal transporter for dopamine: kinetic evidence from studies in vitro and in vivo. J Neurochem 61:764-767.

Meiergerd SM, Hooks MS, Schenk JO (1994a) The striatal transporter for dopamine in the rat may be kinetically upregulated following 3 weeks of withdrawal form cocaine self-administration. J Neurochem 63:1277-1281.

Meiergerd SM, McElvain JS, Schenk JO (1994b) Effects of cocaine and repeated cocaine followed by withdrawal: alterations of dopaminergic transporter turnover with no changes in kinetics of substrate recognition. Biochem Pharmacol 47:1627-1634

Meiergerd SM, Schenk JO, Sorg BA (1997) Repeated cocaine and stress increase dopamine clearance in the rat medial prefrontal cortex. Brain Res 773:203-207.
Pierce RC, Kalivas PW (1997) Repeated cocaine modifies the mechanism by which amphetamine releases dopamine. J Neurosci 17:3254-3261.

Pristupa ZB, McConkey F, Liu F, Man HY, Lee FJS, Wang YT, Niznik HB (1998) Protein kinase mediated bidirectional trafficking an functional regulation of the human dopamine transporter. Synapse 30:79-87.

Reith MEA, Xu C, Chen NH (1997) Pharmacology and regulation of the neuronal dopamine transporter. Eur J Pharmacol 324:1-10.

Segel IH (1993) Enzyme kinetics: behavior and analysis of rapid equilibrium and steady-state enzyme systems, pp 25-29. New York: Wiley.

Tian Y, Kapatos G, Granneman JG, Bannon MJ (1994) Dopamine and $\gamma$-aminobutyric acid transporters: differential regulation by agents that promote phosphorylation. Neurosci Lett 173:143-146.

Uchikawa T, Kiuchi Y, Yura A, Nakachi N, Yamazaki Y, Yokomizo C, Oguchi K (1995) $\mathrm{Ca}^{2+}$-dependent enhancement of $\left[{ }^{3} \mathrm{H}\right]$ dopamine uptake in rat striatum: possible involvement of calmodulin-dependent kinases. J Neurochem 65:2065-2071.

Vaughn RA, Huff RA, Uhl GR, Kuhar MJ (1997) Protein kinase $\mathrm{C}$-mediated phosphorylation and functional regulation of dopamine transporters in striatal synaptosomes. J Biol Chem 272:15541-15546.

Wayment H, Meiergerd SM, Schenk JO (1998) Relationships between the catechol substrate binding site and amphetamine, cocaine, and mazindol binding sites in a kinetic model of the striatal transporter of dopamine in vitro. J Neurochem 70:1941-1949.

Yi S-J, Johnson KM (1990) Effects of acute and chronic administration of cocaine on striatal uptake, compartmentalization, and release of $\left[{ }^{3} \mathrm{H}\right]$ dopamine. Neuropharmacology 29:475-486.

Zhang L, Coffey LL, Reith ME (1997) Regulation of the functional activity of the human dopamine transporter by protein kinase $\mathrm{C}$. Biochem Pharmacol 53:677-688.

Zhu S-J, Kavanaugh MP, Sonders MS, Amara SM, Zahniser NR (1997) Activation of protein kinase $\mathrm{C}$ inhibits uptake, currents and binding associated with the human dopamine transporter in Xenopus oocytes. J Pharmacol Exp Ther 282:1358-1365.

Zimanyi I, Lajtha A, Reith MEA (1989) Comparison of characteristics of dopamine uptake and mazindol binding in mouse striatum. Naunyn Schmiedebergs Arch Pharmacol 340:626-632. 